\title{
Physicochemical characterization and thermal behavior of biodiesel and biodiesel-diesel blends derived from crude Moringa peregrina seed oil
}

\author{
Mohammed Salaheldeen a,b,*, M.K. Aroua ${ }^{a}$, A.A. Mariod ${ }^{\text {c,d }}$, Sit Foon Cheng ${ }^{\text {e, Malik A. Abdelrahman }}{ }^{\text {b,f }}$, \\ A.E. Atabani ${ }^{\text {g,h }}$ \\ a Chemical Engineering Department, Faculty of Engineering, University Malaya, 50603 Kuala Lumpur, Malaysia \\ ${ }^{\mathrm{b}}$ Department of Chemistry, Faculty of Science, Sudan University of Science and Technology, P.O. Box 407, Khartoum, Sudan \\ 'College of Sciences and Arts-Alkamil, King Abdulaziz University, Alkamil, Saudi Arabia \\ d Department of Food Science \& Technology, College of Agricultural Science, Sudan University of Science and Technology, P.O. Box 407, Khartoum, Sudan \\ ¿ Unit of Research on Lipids, Department of Chemistry, Faculty of Science, University of Malaya, 50603 Kuala Lumpur, Malaysia \\ ${ }^{\mathrm{f}}$ Department of Chemistry, College of Medical Science (Turuba), Taif University, Saudi Arabic \\ ${ }^{\mathrm{g}}$ Department of Mechanical Engineering Faculty of Engineering, Erciyes University, 38039 Kayseri, Turke \\ ${ }^{\mathrm{h}}$ Erciyes Teknopark A.Ș, Yeni Mahalle Aşıkveysel Bulvan Erciyes Teknopark, Tekno 3 Binası 2, Kat No: 28, 38039 Melikgazi/Kayseri, Turkey
}

A R T I C L E I N F O

\section{Article history:}

Received 23 July 2014

Accepted 29 December 2014

Available online 21 January 2015

\section{Keywords:}

Moringa peregrina

Biodiesel

Fuel properties

Thermal stability

\begin{abstract}
A B S T R A C T
Moringaceae is a monogeneric family with a single genus i.e. Moringa. This family includes 13 species. All these species are known as medicinal, nutritional and water purification agents. This study reports, for the first time, on characterization of the biodiesel derived from crude Moringa peregrina seed oil and its blends with diesel. The crude oil was converted to biodiesel by the transesterification reaction, catalyzed by potassium hydroxide. High ester content $(97.79 \%)$ was obtained. $M$. peregrina biodiesel exhibited high oxidative stability $(24.48 \mathrm{~h})$. Moreover, the major fuel properties of $M$. peregrina biodiesel conformed to the ASTM D6751 standards. However, kinematic viscosity $\left(4.6758 \mathrm{~mm}^{2} / \mathrm{s}\right)$, density $\left(876.2 \mathrm{~kg} / \mathrm{m}^{3}\right)$ and flash point $\left(156.5^{\circ} \mathrm{C}\right)$ were found higher than that of diesel fuel. In addition, the calorific value of M. peregrina biodiesel $(40.119 \mathrm{MJ} / \mathrm{kg}$ ) was lower than the diesel fuel. The fuel properties of $M$. peregrina biodiesel were enhanced significantly by blending with diesel fuel. In conclusion, $M$. peregrina is a suitable feedstock for sustainable production of biodiesel only blended up to $20 \%$ with diesel fuel, considering the edibility of all other parts of this tree.
\end{abstract}

2015 Elsevier Ltd. All rights reserved.

\section{Introduction}

Fossil fuels reservoirs around the world are declining due to their non-renewable nature. At the same time the demand for energy is, continuously, increasing to meet the needs of the world population, which is growing significantly. As a result, the prices of fossil fuels have increased and, negatively, affected the economies of many countries. Global warming is being caused by the greenhouse gas emissions. Reducing the dependence on fossil fuels will be beneficial, from environmental point of view, since this will reduce the concentration of carbon dioxide in the atmosphere. Therefore, explorations to find new renewable, sustainable and

* Corresponding author at: Department of Chemistry, Faculty of Education, Nile Valley University, P.O. Box 347, Atbra, Sudan. Tel.: +249 122718984

E-mail addresses: Salahch73@gmail.com (M. Salaheldeen), mk_aroua@um.edu. my (M.K. Aroua), basitmariod@yahoo.com (A.A. Mariod), sfcheng@um.edu.my (S.F. Cheng), malikabdalla@yahoo.com (M.A. Abdelrahman), a_atabani2@msn.com (A.E. Atabani)

http://dx.doi.org/10.1016/j.enconman.2014.12.087

0196-8904/๑ 2015 Elsevier Ltd. All rights reserved. economically feasible sources of energy have emerged as a top priority for research to resolve all these problems.

Biodiesel is one of the most promising alternative fuels to replace the conventional petroleum-based fuels with multiple environmental advantages. Biodiesel, popularized as the mono alkyl esters are derived from triglycerides (vegetable oils or animal fats). Transesterification is the most convenient process to convert triglycerides to biodiesel. Transesterification process involves a reaction of the triglyceride feedstock with light alcohol in the presence of a catalyst to yield a mixture of mono alkyl esters [1]. Currently, homogenous basic catalysis, using hydroxides of sodium or potassium, is the common route for industrial production of biodiesel [2].

Biodiesel industry has grown up in the world using edible feedstock such as rape seed, soybean, sunflower and palm oils. Non-edible oils stand as new promising sources of raw materials for biodiesel production, especially in developing countries to satisfy their increasing energy demand [3]. Currently, Jatropha curcas has been promoted as the most promising non-edible source 
for bio-fuel [4]. However, all parts of Jatropha are toxic [5]. Therefore, plantation of such toxic plant for large scale and long term production may raise risks, such as accidental consumption by children or animals. Moreover, the situation is being worsened by spreading Jatropha on the fertile lands in order to improve the yields, as this will reduce water and available space for food crops [6]. Thus, plants that can supply, simultaneously, food and fuel should be given more attention as robust feedstock for bio-fuels. In this respect, Moringa seed oil has emerged as a potential feedstock for biodiesel production, considering the one hundred percent usability of all other parts of this tree [7]. All nutritional values and medicinal usage of Moringa have been comprehensively reported [8]. After oil extraction from the seeds, the residues remain are potential for both water purification and as a fodder [9]

Moringa is a single genus of the Moringaceae family. This family includes 13 species. All these species originated in India and Africa and have been distributed in many other several tropics lately [10]. Moringa oleifera [11-13] and Moringa stenopetala [14] have been reported for biodiesel production. Preliminary study [15] revealed that crude $M$. peregrina seed oil is potential for biodiesel production. M. peregrina oil has high degree of unsaturation, comprised of oleic acid as a major component [16]. Thus, other preliminary studies [17,18], indicated the potential of $M$. peregrina oil for edible purposes and other industrial application, such as hydrogenation, shortening production and others.

M. peregrina is distributed in wide range extending from Egypt, Ethiopia to Somalia, Sudan, the Red Sea region, Palestine and Jordan [19]. M. peregrina as it is very fast growing tree, can reach $3-10 \mathrm{~m}$ in height during only 10 months from the plantation of the seed. It has grayish-green bark, long leaves, and bisexua yellowish white to pink, showy, fragrant flowers. The fruits are elongate capsules, with a beak, glabrous and slightly narrowed between the seeds. The seeds are globose to ovoid or trigonous $[10,19,20]$. Plantations of $M$. peregrina have been assessed as quite promising, with growth reasonably rapid and cultivation easy [15].

The aim of this study is to investigate the properties of $M$. Peregrina biodiesel for the first time. The oil was extracted from $M$. peregrina seeds. The extracted crude oil was converted to biodiesel by the transesterification reaction in one step, catalyzed by potassium hydroxide. The produced biodiesel was blended with diesel fuel No. 2. Physical characteristics of the biodiesel and biodiesel-diesel blends were discussed in the light of the international standards ASTM (American Society for Testing and Materials) D 6751 . The ester content in the produced biodiesel was determined and discussed in accordance to the European Standards EN14214 using the method EN14103.

\section{Experimental}

\subsection{Materials}

M. peregrina seeds were purchased from the Forest National Corporation of the River Nile State in Sudan. The seeds were cleaned to remove damaged seeds, sand, stones, wood and any other foreign materials. The cleaned seeds were packed in plastic bags and stored in a cold room until extraction. Diesel No. 2 was purchased from a local petroleum station in Kuala Lumpur in Malaysia, near University of Malaya. Pure analytical standards of fatty acid methyl esters (FAME), a mixture of (C4-C24) and pure methyl heptadecanoate were purchased from Sigma-Aldrich (Malaysia). All other reagent, like $\mathrm{n}$-hexane $95 \%$, sodium sulfate anhydrous, potassium hydroxide, phenolphthalein indicator, ethanol 95\%, and methanol 99.9\%, were analytical grade and were purchased from Merck (Malaysia). All reagents and standards were used as received without any further drying or purification.

\subsection{Oil extraction}

M. peregrina seeds were crushed by grinder and sieved to less than $1 \mathrm{~mm}$ in size. The meal $(500 \mathrm{~g})$ was placed in a soxhlet extractor. A cotton cloth was used as a thimble to hold the sample. The extractor was fitted with round bottom flask $(5 \mathrm{~L})$ and a condenser. The extraction was carried out using hexane ( $3 \mathrm{~L})$. After $6 \mathrm{~h}$ extraction time, the solvent was recovered by rotary evaporator at $40^{\circ} \mathrm{C}$ under vacuum. The oil was dried with sodium sulfate anhydrous prior to biodiesel production.

\subsection{Biodiesel production}

The average acid value of the extracted $M$. peregrina seed oil was found $(0.68 \mathrm{mg} \mathrm{KOH} / \mathrm{g})$. It was, early, reported that the acid value below $1.0 \mathrm{mg} \mathrm{KOH} / \mathrm{g}$ oil, render the conversion of the vegetable oil to biodiesel feasible by a one step base-catalyzed transesterification reaction without significant mass loss due to saponification [21]. The reaction was carried out in a batch reactor, which consists of a glass jacket reactor $(2 \mathrm{~L})$ equipped with condenser and water bath to control the temperature. $0.600 \mathrm{~L}$ of the oil were placed in the reactor and warmed to $60{ }^{\circ} \mathrm{C}$. Simultaneously, fresh methanolic potassium hydroxide was prepared by mixing 5.267 g potassium hydroxide in $0.150 \mathrm{~L}$ pure methanol. The resultant solution was poured into the reactor after the temperature established at $60{ }^{\circ} \mathrm{C}$. The amounts of the components of the reaction mixture were chosen to afford 6:1 methanol/oil molar ratio and $1 \%(\mathrm{w} / \mathrm{w})$ of oil catalyst. The reaction was allowed to run under continuous stirring for two hours. At the end, the reaction mixture was transferred to a separated funnel where two distinct layers were formed by standing $(12 \mathrm{~h})$. The lower layer contained glycerol and the upper layer contained the methyl ester of the oil. The lower layer was drained and the layer of the biodiesel was washed gently with warm water until the drained washing became neutral, to remove the soaps, methanol, residual glycerol and the other impurities. The residual methanol and water were removed by the means of a rotary evaporator. Finally, the biodiesel was further dried with sodium sulfate anhydrous to remove the traces of water.

\subsection{Infrared spectroscopy}

The conversion of the vegetable oil to biodiesel was investigated by Fourier transform infrared spectroscopy (FTIR). Bruker tensor 27 FT-IR spectrophotometer (Germany), equipped with attenuated total reflectance (ATR) cell that has a ZnSe single crystal, was used to obtain the IR spectra (absorbance mode) in the region 400$700 \mathrm{~cm}^{-1}$ with 24 scans and $4^{-1}$ resolution.

\subsection{Ester content and fatty acid composition determination}

Gas chromatography (GC Shimadzu 2010, Japan) was used to analyze the fatty acid composition of the produced biodiesel. The operating conditions are shown in Table 1 . The retention times of the methyl esters of the sample were compared to those of the standard FAMEs. Quantity of each component was calculated from the relative peak area and considered as a percentage by mass. The ester content in the sample of biodiesel was determined according to the EN14103 method [22], using methyl heptadecanoate as an internal standard. All the values are reported as a mean of duplicate determination.

\subsection{Biodiesel-diesel blending}

Biodiesel-diesel blends were prepared at ambient temperature in glass bottles and homogenized by agitation $(2000 \mathrm{rpm})$ for 30 min. Six blends $(5 \%, 10 \%, 20 \%, 40 \%, 60 \%$ and $80 \% \mathrm{v} / \mathrm{v})$ were 
Table 1

GC conditions for determination of fatty acid composition.

\begin{tabular}{ll}
\hline Property & Specification \\
\hline Injector & Split $1: 50$ at $240^{\circ} \mathrm{C}$ and $1 \mu \mathrm{L}$ injection volume \\
Column & BPX70 $(30 \times 0.32 \mathrm{~mm}$ ID and $0.25 \mathrm{~mm}$ film thickness $)$ \\
Gas currier & Hydrogen $64.4 \mathrm{~K} \mathrm{~Pa}$, total rate flow $59.9 \mathrm{ml} / \mathrm{min}$ and \\
& column flow is $1.1 \mathrm{ml} / \mathrm{min}$ \\
Detector & FID at $260^{\circ} \mathrm{C}$ \\
Heating program & $140^{\circ} \mathrm{C}$ hold $2 \mathrm{~min}, 8^{\circ} \mathrm{C}$ to 165 \\
& $3^{\circ} \mathrm{C} / \mathrm{min}$ to 192 \\
& $8^{\circ} \mathrm{C} / \mathrm{min}$ to 220 holding $12 \mathrm{~min}$ \\
\hline
\end{tabular}

prepared to investigate the effect of blending on biodiesel properties at low and high blend ratios.

\subsection{Fuel properties determination}

Some fuel properties of the crude oil, biodiesel and biodieseldiesel blends were examined according to ASTM D6751. These properties include calorific value, kinematic viscosity, viscosity index, density, cloud point (CP) pour point (PP), cold filter plugging point (CFPP), flash point and oxidative stability. Table 2 shows the description of the equipment and their manufactures, along with the ASTM methods that were used to conduct these analyses in this study. The acid values of the crude $M$. peregrina oil and its biodiesel were determined by titration according to Kuntom et al. [23].

Cetane number $(\mathrm{CN})$ of biodiesel is directly proportional to the length of the carbon chain and inversely to the number of the double bonds. Therefore, it was calculated based on the iodine value (IV) and Saponification number (SN) according to Eq. (1) as reported by Krisnangkura [24]. IV and SN were calculated according to Eqs. (2) and (3) respectively [25]:

$\mathrm{CN}=46.3+(5458 / \mathrm{SN})-(0.225 \times \mathrm{IV})$

$\mathrm{IV}=\sum \frac{560 \times A_{\mathrm{i}} \times D}{\mathrm{MW}_{\mathrm{i}}}$

$\mathrm{SN}=\sum \frac{254 \times D \times A_{\mathrm{i}}}{\mathrm{MW}_{\mathrm{i}}}$

where $A_{\mathrm{i}}, D$ and $\mathrm{MW}_{\mathrm{i}}$ stand for concentration by percentage, number of double bond and molecular weight of each methyl ester.

\subsection{Thermal analysis}

Volatility is one of the most important properties to determine the viability of biodiesel as a fuel regarding engine performance. In this study thermogravimetric analyzer TGAQ500 (TA instruments, USA) was used to investigate the thermal behavior of $M$. peregrina biodiesel and the effects of blending with diesel on its volatility. The sample (5-8 $\mathrm{mg}$ ) was heated from ambient temperature to $600{ }^{\circ} \mathrm{C}$ with a heating rate $10^{\circ} \mathrm{C} / \mathrm{min}$ in an inert atmosphere of pure nitrogen at a flow rate of $100 \mathrm{ml} / \mathrm{min}$. The obtained data were analyzed using the universal analysis 2000 software.

\section{Results and discussion \\ 3.1. Crude oil properties}

Extraction process revealed that $M$. Peregrina seed had an oil content $\sim 26 \%$ of dry base from the whole seed. The extracted oil had very low free fatty acid content $(0.34 \%)$, equivalent to $0.68 \mathrm{mg} \mathrm{KOH} / \mathrm{g}$ oil, eliminating the need of acid pretreatment step as explained in the experimental part (2.3). Table 3 shows some properties of crude $M$. peregrina seed oil in comparison to some common edible and non-edible vegetable oils [13] for biodiesel production. The kinematic viscosity of crude $M$. peregrina seed oil at $40{ }^{\circ} \mathrm{C}$ was found $36.181 \mathrm{~mm}^{2} / \mathrm{s}$, which is 11 times higher than the viscosity of diesel fuel $\left(3.1135 \mathrm{~mm}^{2} / \mathrm{s}\right)$ as reported in Table 5 . Moreover, crude $M$. peregrina seed oil was found to have high flash point $\left(268.5^{\circ} \mathrm{C}\right)$. Flash point is inversely proportional to the volatility of the vegetable oils [26]. Therefore, the transesterification reaction is necessary to improve the viscosity and volatility of crude $M$. peregrina seed oil.

\subsection{Infrared spectra of $M$. peregrina seed oil and its biodiesel}

The conversion of crude $M$. peregrina seed oil to methyl ester and the purity of the produced biodiesel were examined by the FTIR spectroscopy. Fig. 1 displays the FTIR spectra of the crude $M$. peregrina seed oil and its methyl ester. A comparison between the two spectra in the region of $1500-1000 \mathrm{~cm}^{-1}$, showed a significant differences, which are attributed to the replacement of $\mathrm{CH}_{2} \mathrm{O}$ - group in the triglyceride by the $\mathrm{CH}_{3} \mathrm{O}$ - group in the methyl ester. A new peak, which does not exist in the spectra of the oil, appeared in the spectra of the methyl ester at $1435.58 \mathrm{~cm}^{-1}$ due to the deformation vibration of the methoxy group $\left(\mathrm{CH}_{3} \mathrm{O}-\right)$. This peak represents a direct indicator for the conversion of the oil to methyl ester $[27,28]$. Another, significant, difference was observed in the range $1300-1060 \mathrm{~cm}^{-1}$ as a result of the esteric bond (C-O) stretching vibration. In this range, the crude oil showed strong broad peak at $1159.63 \mathrm{~cm}^{-1}$ due to the absorbance of the triple ester group in the triglycerides [28]. Whereas, the methyl ester showed two peaks at $1195.64 \mathrm{~cm}^{-1}$ and $1169.30 \mathrm{~cm}^{-1}$. The new peak at $1195.64 \mathrm{~cm}^{-1}$ is explained by the presence of the methyl group near the carbonyl group. The peak at 1244.47 in the spectrum of the methyl ester is assigned to the asymmetrical stretching of the group $\mathrm{C}-\mathrm{O}-\mathrm{C}$. The same group is noticed at $1236.47 \mathrm{~cm}^{-1}$ in the oil spectrum [29]. The absence of broad peak in the region $2500-3300 \mathrm{~cm}^{-1}$ indicates the very low concentrations of impurities that contain hydroxyl groups such as water, methanol free glycerol and free fatty acids [30]. Moreover, no peak was observed in the region $1650-1540 \mathrm{~cm}^{-1}$ indicating the absence of soap in the

Table 2

List of the equipment used in the fuel properties determination.

\begin{tabular}{llll}
\hline Property & Equipment & Manufacturer & Standard method \\
\hline Kinematic viscosity & SVM 3000-automatic & Anton Paar, UK & D 445 \\
Viscosity index & SVM 3000-automatic & Anton Paar, UK & D2270-04 \\
Density & SVM 3000-automatic & Anton Paar, UK & D 7042 \\
Calorific value & C2000 basiccalorimeter-automatic & IKA, UK & D 240 \\
Cloud point (CP) & Cloud and pour point tester - automatic NTE 450 & Normalab, France & D 2500 \\
Pour point (PP) & Cloud and pour point tester - automatic NTE 450 & Normalab, France & D97 \\
Cold filter plugging point (CFPP) & Cold filter plugging point - automatic NTL 450 & Normalab, France & D 6371 \\
Oxidative stability (OS) & 873 Rancimat - automatic & Metrohm, Switzerland & EN 14112 \\
\hline
\end{tabular}


Table 3

Physical properties of crude M. peregrina seed oil in comparison to some other oils.

\begin{tabular}{|c|c|c|c|c|c|c|}
\hline Property & M. peregrina this study & M. oleifera [13] & Palm [13] & Soybean [13] & Canola [13] & Jatropha [13] \\
\hline Kinematic viscosity at $40^{\circ} \mathrm{C}\left(\mathrm{mm}^{2} / \mathrm{s}\right)$ & 36.181 & 43.4680 & 41.932 & 35.706 & 35.706 & 48.095 \\
\hline Kinematic viscosity at $100{ }^{\circ} \mathrm{C}\left(\mathrm{mm}^{2} / \mathrm{s}\right)$ & 7.9707 & 9.0256 & 8.4960 & 7.6295 & 8.5180 & 9.1039 \\
\hline Viscosity index (VI) & 201.1 & 195.20 & 185.0 & 223.5 & 213.5 & 174.1 \\
\hline Calorific value (MJ/kg) & 39.916 & 39.762 & 39.867 & 39.579 & 39.751 & 38.961 \\
\hline Oxidative stability (h) & 29.255 & 41.7 & 0.08 & 6.09 & 5.64 & 0.32 \\
\hline
\end{tabular}

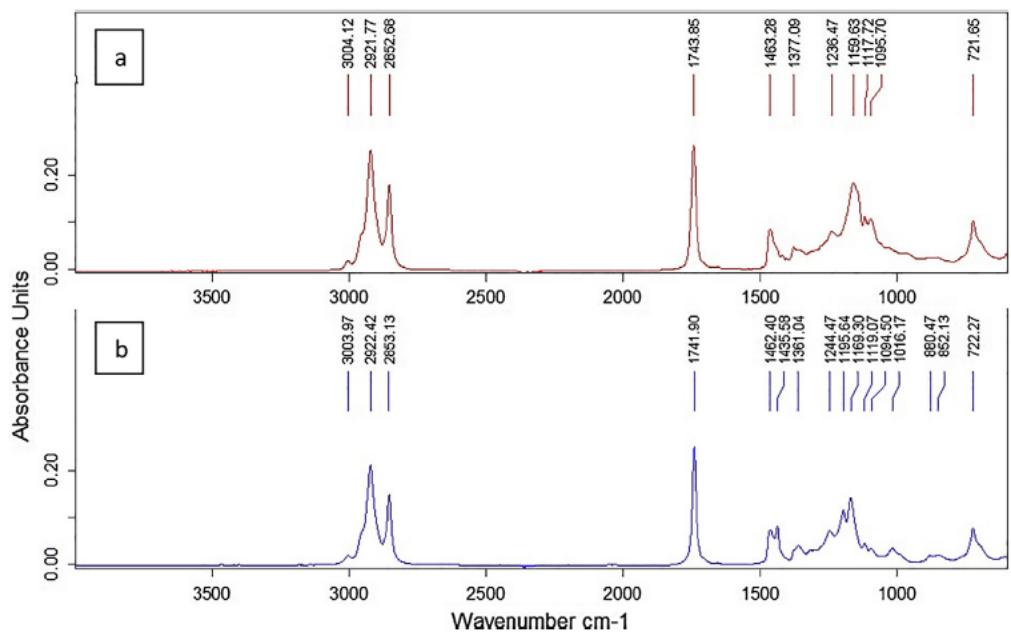

Fig. 1. (a) FTIR spectrum of crude M. peregrina seed oil and (b) FTIR spectrum of $M$. peregrina methyl ester.

biodiesel [33], which indicates that the step of washing was satisfactory. The whole FTIR spectrum of $M$. peregrina methyl ester obtained for this study, is similar to the spectra that were recorded for palm, soybean and sunflower methyl esters [30], indicating that crude $M$. peregrina seed oil is a new feedstock potential for biodiesel production.

\subsection{Ester content and composition of $M$. peregrina biodiesel}

The yield of biodiesel was found $92.33 \%(\mathrm{v} / \mathrm{v})$. The ester conten in the produced biodiesel was determined by the GC analysis according to the EN14103 standard method. The average value of the ester content, obtained from duplicate determination, was $97.79 \%$ with absolute difference $1.1 \%$. EN14103 stated that the absolute difference between two independent single test results shall not be greater than $1.6 \%$. Thus, the value obtained here is satisfactory regarding repeatability. This value of the ester content $(97.79 \%)$ is greater than the minimum value required by the EN14103 (96.5\%). The glycerol portion of the original vegetable oil is usually about $10.5 \%$, thus, values of ester content greater than $97.7 \%$ indicates that the residual total glycerol is lower than the maximum value $(0.24 \%)$ required by the ASTM D6751 [31]. It is concluded here from the GC analysis that the obtained $M$. peregrina methyl ester had high purity.

The composition of $M$. peregrina methyl ester as identified from the GC analysis is presented in Table 4. For the sake of comparison between different species in the same family, Table 4 also includes the fatty acid composition of methyl esters derived from $M$. oleifera [11] and M. stenopetala [13] oils. The prominent feature of all these species is the presence of oleate fatty ester as the dominant component (71-76\%) and very low content $(>5 \%)$ of polyunsaturated fatty esters. Methyl esters that contain a high fraction of

Table 4

Fatty acid composition of $M$. peregrina methyl ester in comparison to $M$. oleifer methyl ester and $M$. stenopetala methyl ester.

\begin{tabular}{lcll}
\hline & $\begin{array}{l}\text { M. peregrina methyl } \\
\text { ester }\end{array}$ & $\begin{array}{l}\text { M. oleifera methyl } \\
\text { ester }^{\mathrm{a}}\end{array}$ & $\begin{array}{l}\text { M. stenopetala methyl } \\
\text { ester }^{\mathrm{b}}\end{array}$ \\
\hline $\mathrm{C} 16: 0$ & 9.08 & 6.50 & 6.10 \\
$\mathrm{C} 16: 1$ & 2.68 & - & - \\
$\mathrm{C} 18: 0$ & 4.04 & 4.40 & 7.50 \\
$\mathrm{C} 18: 1$ & 71.09 & 72.20 & 76.0 \\
$\mathrm{C} 18: 2$ & 4.16 & 1.00 & - \\
$\mathrm{C} 18: 3$ & 0.51 & - & - \\
$\mathrm{C} 20: 0$ & 2.38 & 4.0 & 3.80 \\
$\mathrm{C} 20: 1$ & 1.86 & 2.00 & 1.70 \\
$\mathrm{C} 22: 0$ & 3.13 & 7.10 & 4.40 \\
C24:0 & 1.02 & - & - \\
TFFs $^{\mathrm{c}}$ & 80.30 & 75.20 & 77.70 \\
TMFEs $^{\mathrm{d}}$ & 75.63 & 74.20 & 77.7 \\
TPUFEs $^{\mathrm{e}}$ & 4.66 & 1 & - \\
TSFEs $^{\mathrm{f}}$ & 19.7 & 24.80 & 22.3 \\
VLCFEs $^{\mathrm{g}}$ & 8.39 & 13.10 & 9.90 \\
\hline
\end{tabular}

Ref. $[11]$

b Ref. [14].

c Total unsaturated fatty esters.

d Total monounsaturated fatty esters.

e Total poly unsaturated fatty esters.

f Total saturated fatty esters.

$\mathrm{g}$ Very long chain fatty esters.

Link to Full-Text Articles :

http://www.sciencedirect.com/science/article/pii/s0196890414011364 